\title{
Paruman Tapakan Barong dalam Ritual Tapak Pertiwi
}

\author{
I Wayan Dana ${ }^{1}$ \\ Jurusan Tari, Fakultas Seni Pertunjukan, Institut Seni Indonesia Yogyakarta
}

\begin{abstract}
Paruman Tapakan Barong on Tapak Pertiwi Ritual. Ritual tapak pertiwi siklus pelaksanaan ritual tahunan dalam perhitungan kalender Bali, diselenggarakan terpusat dalam Paruman Tapakan Barong di Pura Natar Sari Apuan. Pelaksanaan ritual ini dihadiri oleh berbagai bentuk tapakan barong yang datang dari berbagai daerah se wilayah Bali Tengah yang memperoleh kekuatan pasupati di Pura Natar Sari Apuan. Aktivitas ritual ini bermakna menyatunya kekuatan dewa sebagai simbol (purusa) dengan dewi pertiwi simbol (pradana). Pertemuan kedua unsur kekuatan suci itu melahirkan gerak kehidupan, menyucikan alam semesta dari segala pengaruh negatif yang mengancam hidup dan kehidupan umat manusia di alam semesta ini. Oleh karena itu, masyarakat Hindu di Bali menghadirkan berbagai bentuk ritual keagamaan untuk menghormati menyatunya energi alam positif dan negatif dalam beragam wujud, termasuk ritual tapak pertiwi.
\end{abstract}

Key worsds: Paruman Tapakan Barong, Ritual, Tapak Pertiwi

\section{Pendahuluan}

Pada lingkungan aktivitas masyarakat Bali, paruman pada umumnya dimaknai sebagai sebuah kegiatan pertemuan atau (sangkep bahasa Bali) yang bersifat sekuler, melibatkan para anggota masyarakat desa. Sangkep biasanya dilaksanakan secara periodik dan temporer. Kegiatan ini pada umumnya diadakan di sebuah ruang publik, seperti balai banjar dengan tujuan untuk memperoleh suatu kesepakatan dari warga desa, mengenai suatu rencana kegiatan, tata aturan (awig-awig), pelaksanaan upacara sampai pada persoalan sosial lainnya. Namun demikian, Paruman Barong dimaknai sebagai sebuah peristiwa sakral religius yang dilakukan di pura. Paruman Barong melibatkan benda-benda sakral berupa barong dan rangda dari berbagai daerah di Bali.

Paruman Barong melibatkan barong-barong dan rangda yang memiliki keterkaitan antara satu barong dengan barong lainnya dibedakan menjadi empat tipe hubungan berdasarkan (1) barong yang berasal dari satu bahan kayu yang sama; (2) barong yang dibuat berasal dari seorang pematung atau sangging yang sama; (3) barong yang memperoleh kekuatan magis dari satu tempat pasupati; dan (4) barong yang memiliki keterkaitan dengan desa pemilik (penyungsung) barong.
Tradisi paruman merupakan sebuah peristiwa sosial budaya yang kaya dan strategis serta efisien untuk mengadakan pembinaan anggota masyarakat secara terorganisasi termasuk memupuk kehidupan berkesenian. Masyarakat Bali pada umumnya sangat kuat mempertahankan kehidupan ritual yang digunakan sebagai masa introspeksi diri secara berkesinambungan terutama pada pertemuan-pertemuan yang berkaitan dengan ritual keagamaan (Sujana, 1994: 50—58 dan Triguna, 1994: 73-89).

Agar memperoleh gambaran utuh pada pendahuluan ini, maka selain diungkap tentang paruman, dipandang perlu memperjelas topik mencakup Tapakan Barong; Pura Natar Sari Apuan, Baturiti Tabanan; dan Ritual Tapak Pertiwi. Pertama, Tapakan Barong, yang terdiri dari dua kata yaitu tapakan dan barong, tetapi menghadirkan satu rangkaian kesatuan makna. Tapakan secara simbolis bermakna kendaraan atau linggihan, tempat para dewata bersemayam. Barong sebagai benda sakral dipercaya oleh masyarakat penyungsung barong, menjadi tempat masuknya enegi alam, sumber kekuatan dewata yang menguasai semesta beserta isinya.

Kata barong diungkap oleh para budayawan maupun pakar seni pertunjukan Bali. Mereka menjelaskan bahwa kata barong berasal dari

1 Alamat korespondensi: Prodi Seni Tari ISI Yogyakarta. Jalan Parangtritis KM. 6,5 Sewon, Yogyakarta 55001. Telepon 0274-375380. E-mail: iwayandana@isi.ac.id 
barwang yang dalam bahasa Jawa Kuno berarti beruang. Kata itu dijumpai dalam kakawin Ramayana (12.61); Sumanasantaka (159.3); Sutasoma (95.6); dan Arjuna Wijaya (10.14) seperti, Singa Barong (singa barwang alayu) (Zoetmulder dalam Titib, 2003: 417). Barong selanjutnya diekspresikan dengan berbagai wujud/ bentuk oleh para seniman dari setiap generasi hingga kini, sehingga berkembang beberapa jenis barong yang terpelihara dengan baik di Bali.

Barong berdasarkan Kanda Empat Buta (2000) memuat swadarmaning sang catur sanak, yaitu empat saudara yang meliputi Anggapati, Prajapati, Banaspati dan Banaspatiraja. Berpijak dari catur sanak itu barong sama dengan unsur cair yang berasal dari ari-ari berkedudukan di sebelah utara yang dijuluki dengan Banaspatiraja. Banas berarti banyu, banyu yang dimaksud adalah air. Air itu dewanya adalah Visnu, yang menguasai arah/sebelah utara. Oleh karenanya, Dewa Visnu dijuluki juga maha ibapa yang memelihara semua kehidupan. Wujud Banaspatiraja dikenal dalam lingkungan budaya Hindu di Bali sebagai Barong Keket dalam berbagai gaya dan bentuk, namun esensinya sama sebagai pelindung (Ida Pedanda Gede Putera Bajing, 2007: 13-20).

Barong, seperti diungkap di atas pada dasarnya mencakup karya seni yang diekspresikan oleh manusia maupun seniman melalui berbagai media seperti seni rupa dan pertunjukan, maupun seni mediarekam. Barong sebagai media ungkap seni pertunjukan ada berbagai jenis barong di antaranya dimainkan oleh dua orang pemain, seperti Barong Keket yang menyerupai wujud harimau tetapi tidak persis; Barong Macan (wujud harimau); Barong Bangkung (wujud induk babi); Barong Bangkal (wujud babi jantan); Barong Asu (wujud anjing); Barong Gajah (wujud gajah). Beberapa jenis barong yang dimainkan oleh seorang penari secara terpisah, seperti Barong Landung yang terdiri atas tokoh Ratu Lanang yang disebut dengan Jro Gede (Barong Laki), dan Ratu Luh (Barong Perempuan); Barong Blasblasan sering juga disebut Barong Kedingkling yang mengenakan topengtopeng Wayang Wong dari epos Ramayana (Bandem, 1982: 32-36 dan Dibia, 1999: 25-31).

Pura Natarsari Apuan Baturiti Tabanan merupakan tempat suci umat Hindu yang berada di
Desa Apuan, Kecamatan Baturiti, Daerah Tingkat II Kabupaten Tabanan Bali. Keberadaan pura ini sangat strategis di tengah perkampungan sehingga kawasan suci utama atau jeroan, madiya, dan nista mandala terlindungi oleh masyarakat setempat. Pura Natarsari diagungkan sebagai kahyangan jagat tempat berlangsungnya paruman Tapakan Barong dalam ritual Tapak Pertiwi. Pelaksanaan paruman ini dilangsungkan setiap 6 (enam) bulan sekali, yang jatuh pada hari Sabtu (Saniscara Kliwon wuku Klurut) atau dikenal dengan sebutan Tumpek Klurut, sesuai dengan perhitungan kalender Bali. Ruang dalam (Utama mandala) Pura Natarsari cukup luas, sehingga memadai digunakan sebagai tempat (pusat) pelaksanaan ritual Tapak Pertiwi.

Ritual Tapak Pertiwi suatu ritual keagamaan yang menggunakan media Barong maupun Rangda atau Topeng-Topeng upacara sebagai kendaraan dewata se Bali Tengah, disertai sejumlah sesaji hadir bersama-sama menyaksikan alam semesta beserta isinya. Tapak Pertiwi bermakna pertemuan alam dewata (swah loka) dengan alam bawah (bhur loka). Alur pertemuan itu melalui perantara waktu tengah malam sebagai alam tengah (bwah loka). Pelaksanaannya diselenggarakan pada tengah malam (pukul 24.00) tepat waktu setempat. Ritual Tapak Pertiwi diadakan di ruang dalam (jeroan) Pura Natarsari Apuan. Seluruh tapakan Barong berkumpul (parum) bersama dengan mengambil posisi melingkar dan mengelilingi sesaji Tapak Pertiwi. Pelaksanaan ritual ini dipimpin oleh pengetua atau orang yang disucikan (bahasa Bali: pamangku) Pura Natarsari dibantu oleh seluruh pamangku dan penyangga Barong yang mengikuti paruman.

Berpijak dari uraian di atas, muncul beberapa masalah yang perlu dikaji lebih lanjut atau mendapat jawaban secara komprehensif. Paruman Barong di Pura Natarsari Apuan, tergambar bahwa terjadi suatu gerakan pertemuan yang sentralistik dari berbagai jenis barong, yang datang dari berbagai desa adat penyungsung barong se Bali Tengah. Tampak bahwa pelaksanaan Paruman Barong yang berlangsung begitu semarak dan beragam terpusat di Pura Natarsari yang memiliki kekuasaan sentripetal sentralistik maupun sentrifugal. Aktivitas Paruman Barong ini menjadi suatu peristiwa silang budaya dan seni yang melahirkan rasa hormat dan penghargaan terhadap keragaman 
budaya, sehingga memunculkan beberapa hal yang menarik untuk dikaji, yakni (1) Pelaksanaan Paruman Barong di Pura Natarsari Apuan sebagai ritual Tapak Pertiwi dan (2) Makna Paruman Barong yang terpusat di Pura Natarsari Apuan dalam ritual Tapak Pertiwi yang diikuti oleh Barong se Bali Tengah.

\section{Pentinganya Pelaksanaan Ritual Keagamaan di Bali}

Kegiatan ritual yang memanfaatkan seni pertunjukan merupakan ungkapan manusia sebagai upaya berkomunikasi dengan penguasa di atas yang tidak tampak. Pada umumnya hal itu diungkap dalam bentuk pelaksanaan upacara suci (Kusmayati, 1990: 2-3) sebagai sebuah pertemuan bagi sesama warga masyarakat yang tampak. Realitas itu menunjukkan bahwa di Bali, kesenian merupakan bagian kegiatan yang tak terpisahkan dari setiap pelaksanaan upacara keagamaan. Kesenian yang diekspresikan manusia sebagai suatu cermin dari budaya agama dan sastra agama Hindu (Wiana, 1993: 61-116 dan Pendit, 1993: 45-51). Dengan demikian, agama merupakan gerakan estetik terlepas dari kewahyuan yang senantiasa memanggil dan menyentuh perasaan manusia melalui metafor, logika, serta bahasa estetik (Salad, 2000: 22-29). Kenyataan seperti itu dengan mudah dapat dibaca dalam teks-teks kitab suci, tradisi puitik, seperti nyanyian (kakawin atau kakidungan), kebaktian, dan dongeng-dongeng mitologis sebagai suatu pemahaman simbolik mengenai ajaran agama. Ungkapan seperti itu selain membangkitkan rasa indah, tampak terjadi pula penyatuan antara kekuatan kebenaran, kebaikan, dan keindahan (Triguna, 2003: xiii-xviii dan Agung, 2006: 8).

Aktualisasi hubungan simbol dengan pernyataan estetik itu dalam tingkat tertentu berhasil diciptakan sesuatu tatanan realitas kultural (Salad, 2000: 22-29 dan Read, 2000: 5-39). Transformasi estetik, seperti keindahan melodi kakawin, kakidungan, gemuruh lagu (tatabuhan) gamelan, gemulai gerak-gerak tarian, dan tatanan berbagai bentuk sesaji, efek pengucapan doa ( $p$ uja mantra) pendeta atau pemangku menyatu padu mencapai puncak estetik yang tidak tertandingi oleh kebudayaan manapun. Kehadiran aktivitas seperti itu tampak pula bahwa para empu, maharesi di masa lalu berhasil mengadaptasi butir-butir ajaran agama Hindu ke dalam simbolsimbol, seperti bentuk pewayangan, gamelan, patung, penataan sesaji, pengaturan bangunan tempat suci, dan aneka ragam ekspresi kesenian di dalam setiap pelaksanaan maupun praktekpraktek ritual keagamaan, termasuk penampilan berbagai kesenian (Dibia, 1985: 61-65 dan Salad, 2000: 22) yang diwariskan oleh leluhur hingga kini.

Warga masyarakat Bali pada umumnya termasuk para seniman melakukan korban suci yang tulus ikhlas (yadnya) melalui berbagai aktivitas kesenian. Ber-yadnya dan berkesenian menjadi satu kesatuan ungkapan yang tidak dapat dipisahkan dalam kepentingan pelaksanaan yadnya. Persembahan kepada Sang Pencipta diwujudkan melalui berbagai media karya seni, menjadi bagian utama kultur masyarakat Hindu di Bali dan di Indonesia. Melakukan berbagai aktivitas keagamaan dengan ekspresi seni dalam pelaksanaan yadnya adalah ungkapan yang menuntun manusia agar lebih terfokus pada jalan penyerahan diri (bhakti) dan perbuatan (karma), termasuk pelaksanaan ritual tapak pertiwi (Putra, 1982: 2-10). Hal itu dijalankan untuk mencapai kesatuan yang harmonis antara manusia, alam, dan Tuhan. Melaksanakan yadnya di kayangan tiga, yaitu: Desa, Puseh, dan Dalem, maupun kahyangan jagat, seperti memuja Sang Hyang Widhi dalam aneka manifestasinya adalah kewajiban masyarakat Bali pada umumnya (Titib, 2003: 100). Yadnya bagi masyarakat Hindu adalah media untuk mengabdi (ngaturangayah) dengan menunjukkan keterampilan mereka dalam berbagai karya dan kreasi seni warisan nenek moyang, maupun kreasi baru yang mereka hadirkan sebagai wujud kemampuan adaptatif terhadap perubahan zaman.

Tradisi meyadnya sebagai aktivitas ritual menjadikan Bali memiliki kesenian yang sangat beragam jenisnya, tercakup dalam bidang seni pertunjukan maupun seni rupa. Aktivitas ritual dan seni berhubungan dengan berlangsungnya yadnya melahirkan bentuk-bentuk dan gaya seni Bali yang spesifik (Mantra, 1996: 35-42). Aspek ritual melahirkan berbagai kesenian yang berfungsi sakral dan keramat. Di Bali, kesenian yang berkaitan langsung dengan upacara keagamaan disebut seni ritual (wali), seperti tari Rejang, Sanghyang, Pendet, Baris, Barong, dan 
banyak lagi yang lainnya. Sifat wali dari sebuah kesenian itu tergantung dari tempat, waktu dan kondisi masyarakat pendukungnya. Kesenian yang dianggap sakral bersifat tidak kekal, namun yang terpenting benar-benar dapat memberi legitimasi terhadap berlangsungnya yadnya yang dilaksanakan oleh umat beragama (Putra, 1982: 5-10 dan Bandem, 1991: 8-18) meliputi panca yadnya, yaitu lima kelompok korban suci mencakup dewa yadnya pemujaan kepada Tuhan Yang Maha Kuasa, pitra yadnya adalah bakti kepada leluhur, resi yadnya menghargai para Bhagawanta, manusa yadnya memelihara manusia sejak lahir hingga mati dan bhuta yadnya, yaitu menjaga kekuatan negatif alam makro maupun alam mikro yang memotivasi lahirnya kreativitas seni (Putra, 1982: 5-10 dan Widana, 2002: 37-38).

Kesenian Barong dan Rangda sebagai seni wali berada dalam lingkup tata aturan yang mengikat sejak proses pembuatannya, penyimpanan, hingga dipertunjukkan berlaku proses sakralisasi (Pandji, 1975/1976: 45-61 dan Pitana, 2006). Oleh karena itu, barong dimaknai sebagai simbol pelindung yang menjaga wilayah masyarakat penyungsung. Di samping itu, barong juga dianggap sebagai simbol lingga sthana dewa yang dipuja. Dalam kehidupan di Bali lazim disebut milik $(d u)$ atau petapakan dewata (Anandakusuma, 1986: 48, 157, dan 192). Sebagai $d u$ para dewata, maka barong sangat dihormati sehingga disebut dengan ungkapan Ratu Gede Dalem, Ratu Mas, Ratu Sakti, Ratu Ngurah, Ratu Ngurah Sakti, dan lainnya tergantung tradisi budaya serta kerpercayaan masyarakat setempat.

Barong merupakan salah satu kesenian sakral yang dapat dikaji dari dua aspek yakni seni rupa dan seni pertunjukannya. Dari aspek seni rupa, bentuk barong divisualisasikan lewat berbagai media, seperti seni patung, lukis, kriya, dan seni media rekam. Visualisasi bentuk barong menjadi lebih mantap dan hidup ketika diperankan dalam berbagai genre seni pertunjukan Bali, seperti dramatari Calonarang (Goris, 1986: 9), Pelegongan, dan Bebarongan. Kesenian barong baik seni rupa maupun pertunjukan termasuk kelompok kesenian tradisional Bali yang ada sejak zaman pra Hindu dan hingga kini terpelihara serta terus berkembang (Monografi Daerah Bali, 1976: 116-117 dan Bandem, 1982: 32-
36). Perkembangan kesenian Barong berjalan sesuai interpretasi dan pengalaman masyarakat pendukungnya yang berpijak pada landasan agama, kehidupan rohani mendalam, merakyat, dan selalu berpegang pada spiritualitas.

Barong bagi masyarakat Bali selain dipercaya sebagai pelindung, juga diyakini sebagai simbol kebaikan yang memiliki spirit ritual keagamaan dan digunakan sebagai sarana penyucian alam semesta. Kekuatan magis bayu barong biasanya terletak pada punggalan khususnya mata, gigi, dan bulu janggut barong yang dibuat dari rambut manusia (Pandji, 1975/1976: 45-61). Jika di suatu desa penyungsung barong terjangkit wabah penyakit, maka pada saat itu pemangku memohon air suci keselamatan di depan altar tempat penyimpanan barong. Pemangku bersemedi memadukan tenaga (bayu), perkataan (sabda), dan pikiran (idep) menyatu melalui kekuatan sakti barong, kemudian dilanjutkan dengan merendam bulu janggut barong pada air suci itu. Air suci itu diyakini memiliki kekuatan gaib, kemudian dipercikkan kepada warga masyarakat yang terjangkit wabah. Ada pula barong disungsung dan diarak langsung ke wilayah desa yang terkena bencana, salah satu lewat ritual tapak pertiwi.

\section{Paruman Barong: Ritual Tapak Pertiwi}

Dua atau tiga bulan sebelum Budha Kliwon Wuku Klurut atau Tumpek Klurut para penyungsung Barong Kedingkling Pura Natarsari menuju ke Pura Pucak Padang Dawa dan selanjutnya mengunjungi desa-desa barong yang memperoleh pasupati barong di Pura Natarsari Apuan (Sudarsana, 2001: 24). Kunjungan ini bermaksud mengundang tapakan-tapakan barong tersebut untuk menghadiri Paruman Barong yang dilaksanakan setiap Saniscara Tumpek Klurut di Pura Natarsari. Ritual melelungan ini dipandang oleh para pengemong dan penyungsung barong adalah kunjungan sebagai wujud undangan untuk mengikuti parum dan menjalankan ritual Tapak Pertiwi sesuai waktu yang ditentukan. Kemudian Barong Kedingkilng kembali ke Pura Natarsari untuk mempersiapkan segala keperluan pujawali penyambutan, datangnya setiap peserta Paruman Barong dari berbagai wilayah se Bali Tengah.

Tepat pada hari Saniscara Tumpek Klurut merupakan bagian inti atau puncak penyelenggaraan Paruman Barong yang pada tengah malam 
melakukan ritual Tapak Pertiwi. Adapun prosesi prosesi ritual seperti berikut: (1) nangiang tapakan Barong Kedingkling Pura Natarsari; (2) tedun melasti ke segara Batubolong; (3) ngelinggihang tapakan Barong Kedingkling setelah datang dari melasti; (4) menyambut kedatangan seluruh tapakan barong yang memperoleh pasupati barong di Pura Natarsari Apuan. Kedatangan tapakan barong silih berganti untuk mengikuti Paruman Barong yang menyatu di Pura Natarsari Apuan; (5) seluruh tapakan barong mesuci di Pura Beji; (6) Sesaji penyambutan (kehaturang sesaji pemendak) dan tapakan barong di tempatkan (dilinggihkan) di Bale Paruman Agung, dilanjutkan pada tengah malam dilaksanakan ritual Tapak Pertiwi. Pada hari Minggu (Redite Umanis) diselenggarakan ritual purwadaksina barong, dan dilanjutkan dengan persembahan sesaji tebasan kepada seluruh barong peserta paruman. Pada Senin (Somo Pahing) dilaksanakan persembahan sesaji penganyar di setiap pelinggih tapakan barong baik di pagi, siang maupun malam hari.

Pada hari ketiga, yaitu Selasa (Anggara Pon) merupakan bagian akhir atau prosesi penutupan Paruman Barong dalam ritual Tapak Pertiwi. Seluruh barong peserta paruman menjalankan ritual pamitan, dari Natarsari, selanjutnya mulai meninggalkan pura menuju daerahnya masing-masing. Pada malam harinya di Pura Natarsari dilaksanakan ritual penyineban Barong Kedingkling dan Śiva Pasupati (Sudarsana, 2001: 27-29) ditempatkan kembali di penyimpanan masing-masing. Ritual penyineban ini menandakan berakhirnya seluruh rangkaian pelaksanaan Paruman Barong yang inti utamanya ritual Tapak Pertiwi. Dengan demikian, warga masyarakat pelaksana paruman juga kembali ke rumah mereka masing-masing.

\section{Pelaksanaan Ritual Tapak Pertiwi}

Selesai acara mesuci seluruh tapakan barong beserta para pengiring kembali ke Pura Natarsari Apuan dan menempatkan kembali tapakan barong sesuai tempatnya (pelinggih). Pada kesempatan itu para pengiring tapakan barong mendapat kesempatan beristirahat sejenak sambil menikmati makan malam dengan jalan mengambil (nunas) di dapur umum yang disiapkan oleh panitia. Apabila para pengiring tidak berkeinginan nunas, mereka dapat membeli sendiri makanan atau minuman, sesuai kemampuan dan keinginan mereka masingmasing kepada pedagang di sekitar luar ( $j a b a$ sisi) pura, sambil menunggu pelaksanaan ritual Tapak Pertiwi.

Pada saat tapakan barong dilinggihkan, di jaba sisi terselenggara berbagai bentuk seni pertunjukan, seperti Calonarang, Kekebyaran di dua tempat yang berbeda. Sajian tarian maupun dramatari ini utamanya untuk memeriahkan suasana menyambut pelaksanaan puncak ritual tapak pertiwi pada tengah malam Sabtu (Saniscara Kliwon) menjelang Minggu (Redite Umanis). Ketika kesenian dipergelaran di jaba sisi pura, maka pada saat itu pula di jeroan pura dipersiapkan dan ditata seluruh sesaji yang dibutuhkan berkaitan dengan ritual tapak pertiwi. Setelah keperluan sesaji ditata lengkap oleh para ahli (tukang banten) bersama pamangku, maka tiba waktunya diselenggarakan ritual Tapak Pertiwi.

Seluruh tapakan barong diturunkan kembali dari Balai Paruman, bersama-sama menuju pusat sesaji Tapak Pertiwi. Tapakan Barong ditata melingkar, mengelilingi sesaji Tapak Pertiwi, diatur oleh Pamangku Pura Natarsari, tetua (penyarikan) bersama para Pamangku Barong peserta ritual. Seluruh tapakan Barong dan Rangda maupun topeng-topeng upacara mendapat seperangkat media suci berupa kain putih-kuning, hiasan berupa (karawista, orti), bunga cempaka, dan benang tebus sebagai sarana menghias tapakan serta percikan air suci oleh para pamangku yang bertugas. Media itu dimaksudkan sebagai lambang kesakralan, sehingga memungkinkan bagi tapakan barong berkomunikasi secara spiritual atas kekuatan Tuhan kepada masyarakat penyungsung.

Tuhan atau Sang Hyang Widhi Wasa yang sakral diyakini hadir di dalam suasana religius dan pada benda-benda sakral, seperti barong dan rangda maupun topeng-topeng upacara yang disucikan. Karena sifat transendensinya, dengan cara seperti ini kekuatan Tuhan diserap, sehingga menjadi duniawi, yang tak teraba menjadi teraba. Berkat lambang itu dimungkinkan terjadi kontak manusia dengan Tuhan, yang membuat mereka percaya, merasa kuat, nyaman, dan sejahtera dalam kehidupan lahir batin (Hendropuspito, 1983: 43 dan Supriyono, 2005: 89-91).

Seusai upacara ritual sesaji ayaban Tapak Pertiwi, semua tapakan barong kembali ke tempat mesayuban masing-masing dengan menginjak 
hamparan kain putih yang terbentang memanjang di depan sesaji menuju linggih masing-masing tapakan barong sesuai ruang gerak para penyungsungnya. Hal ini merupakan lambang kehadiran (nyomia) yaitu pembersihan alam yang kotor disucikan kembali, sehingga menjadi bersih secara spiritual. Jika alam semesta dipercaya suci, bersih kembali, maka kehidupan harmonis antar manusia dengan Tuhan, manusia dengan sesama manusia, dan manusia dengan alam sekeliling terwujud. Oleh karena itu, ritual Tapak Pertiwi dijalankan secara berulang setahun sekali untuk memperbaharui dan mengukuhkan kembali kesucian, sehingga keseimbangan maupun keselarasan manusia dengan alam senantiasa terpelihara dengan semestinya. Salah satu aktivitas ritual Tapak Pertiwi di Pura Natarsari terlihat seperti berikut.

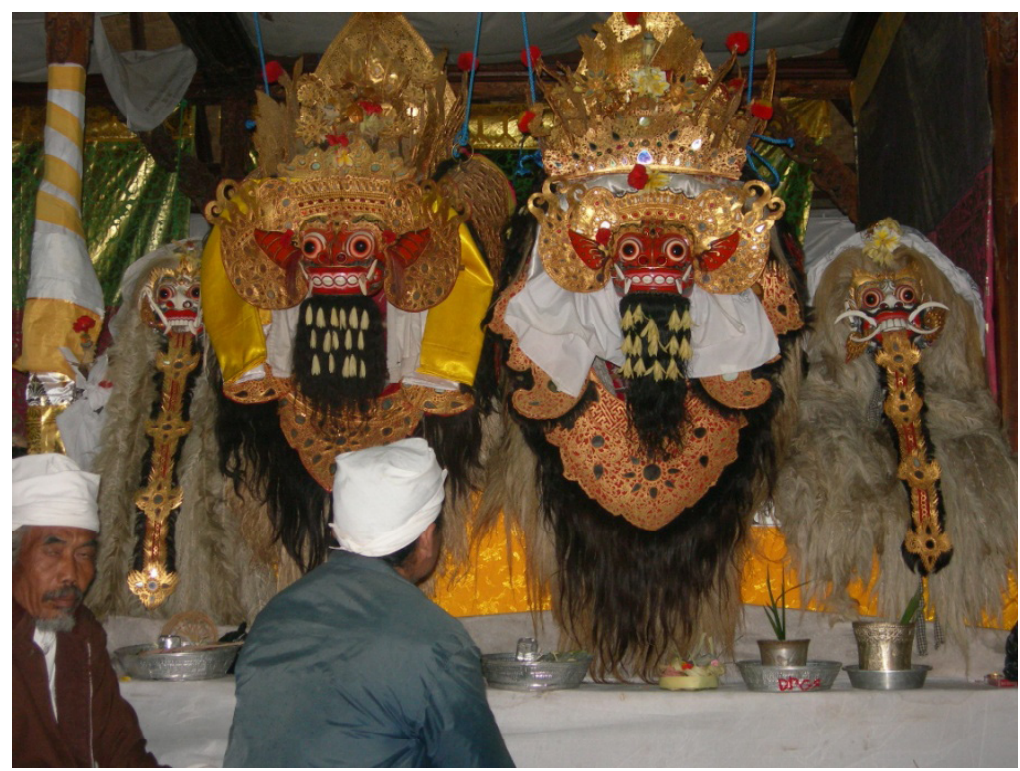

Gambar 1. Tapakan Barong Paruman di Pura Natarsari Apuan saat menunggu kesiapan ritual Tapak Pertiwi (Foto: I Wayan Dana, 2009).

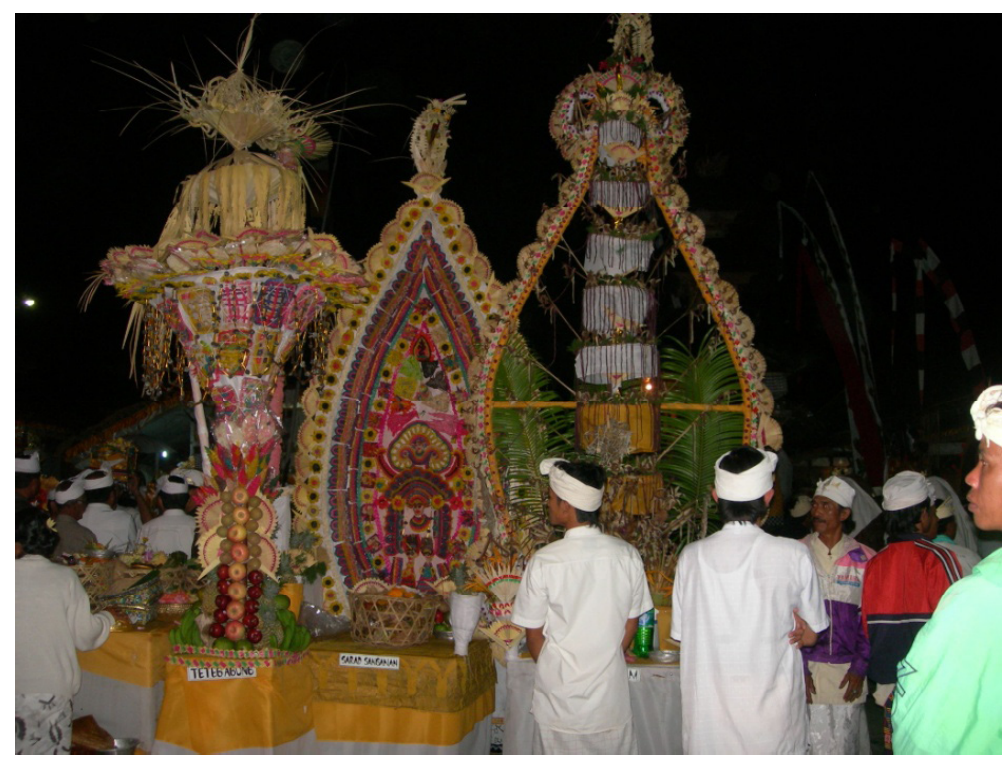

Gambar 2. Persiapan sesaji Tapak Pertiwi, sebelum Tapakan Barong turun mengelilingi sesaji

(Foto: I Wayan Dana, 2009). 


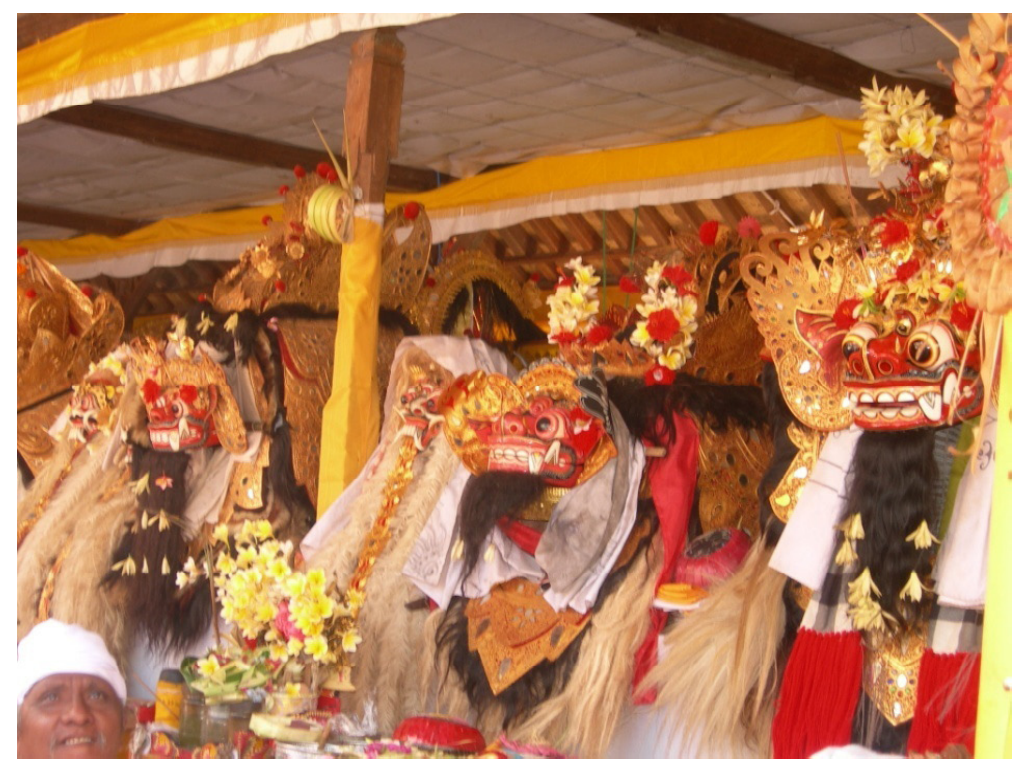

Gambar 3. Tampak sebagian Tapakan Barong dari berbagai daerah se Bali Tengah berkumpul di Pura Luhur Natarsari Apuan Mengikuti Ritual Tapak Pertiwi (Foto: I Wayan Dana, 2009)

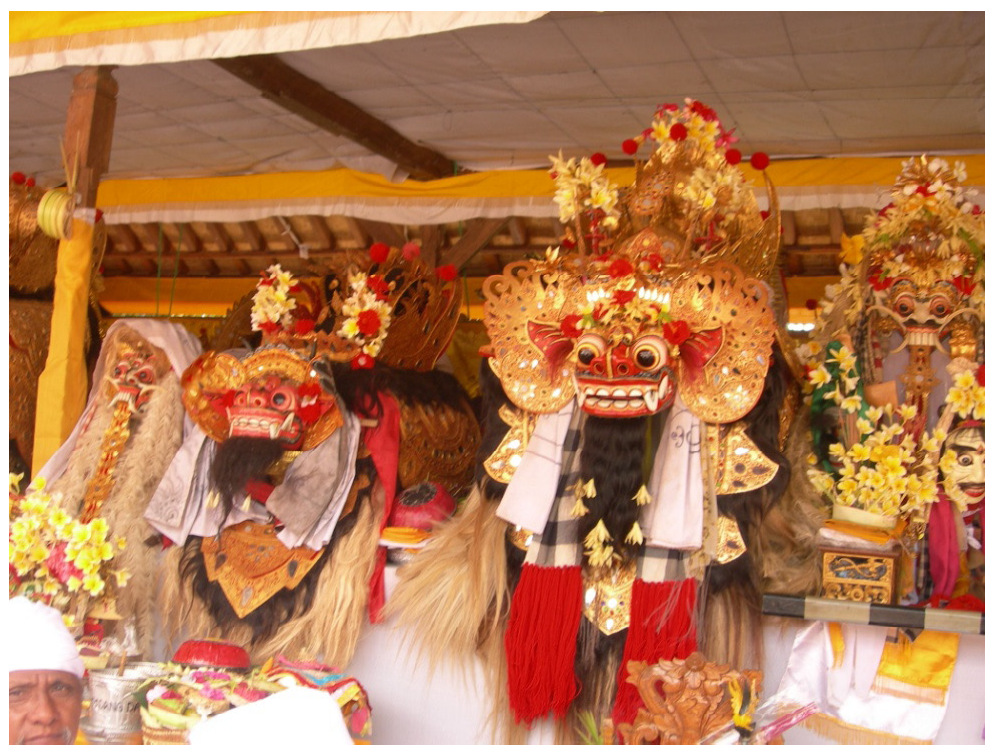

Gambar 4. Tampak sebagian Tapakan Barong dari berbagai daerah se Bali Tengah berkumpul di Pura Luhur Natarsari Apuan kembali ke tempat semula setelah mengikuti Ritual Tapak Pertiwi (Foto: I Wayan Dana, 2009)

\section{Makna Tapak Pertiwi}

Waktu tengah malam merupakan pergantian atau proses berjalanya sang waktu berdasarkan perhitungan kalender Bali. Oleh karena itu, waktu itu dipandang penting dan suci dalam pelaksanaan ritual tertentu, seperti ritual tapak pertiwi. Pada tengah malam, seluruh kegiatan manusia beristirahat sejenak, maka di kala itu para dewata turun ke bumi mengadakan pertemuan suci untuk meneruskan gerak kehidupan yang seimbang dan harmonis agar kehidupan berkesinambungan terus berjalan.

Tapakan Barong yang dipercaya sebagai lambang dewata memiliki kekuatan positif pada saat ritual tapak pertiwi dipertemukan dengan Dewi Tanah (pertiwi), mengandung kekuatan negatif. Pertemuan kekuatan positif dengan negatif menimbulkan energi dahsyat yang mampu menghidupkan segala kehidupan di alam semesta. Energi yang lahir dari gerak positif dan negatif 
menjadi konsep rwabhineda mencakup kekuatan maskulin-feminin (purusa-pradana), baik-buruk (dharma-adharma), arah utara-selatan (kaja-kelod) atau warna hitam-merah, dan juga timur-barat (kangin-kauh) dengan warna putih-kuning, atasbawah (akasa-pertiwi), siang-malam (selid-sanja) dan dua bentuk keseimbangan lainnya dipuja dan dihormati oleh masyarakat Hindu di Bali. Kekuatan dua itu menjadi lambang hidup sejak budaya peramu hingga peladang, pesawah hingga budaya maritim di Nusantara ini.

Paruman Barong di Pura Natarsari Apuan yang berintikan ritual tapak pertiwi memiliki makna yang cukup dalam untuk dipahami oleh masyarakat yang menjalankan maupun tuntunan bagi kehidupan ini agar senantiasa menghormati energi alam dalam berbagai wujud pelaksanaan ritual. Sumber yang berkaitan dengan alam menyebabkan terjadinya keharmonisan hubungan antara manusia dengan Tuhan, hubungan manusia dengan alam lingkungan, dan hubungan manusia dengan sesamanya, seperti dalam tri hita karana (Atmodjo, 1986: 48 dan Kerepun, 2007: 129-141). Penerapan ajaran ini dalam kehidupan umat Hindu di Bali secara mantap, kreatif, dan dinamis terwujud dalam kehidupan yang harmonis, meliputi pembangunan manusia seutuhnya yang astiti bhakti kepada Sang Hyang Widhi. Ungkapan astiti bhakti kepada Tuhan juga diimplementasikan dalam perbuatan cinta terhadap kelestarian bumi (pertiwi), lingkungan alam semesta, serta menjalankan hidup rukun, dan damai dengan sesama umat manusia (Mantra, 1996: 26-40 dan Sutristo, 2005: 183-184).

\section{Penutup}

Berbagai ritual keagamaan dilakukan oleh masyarakat Hindu di Bali untuk menghormati alam semesta agar energi positif maupun negatif dari beragam wujud memberikan kesejahteraan hidup umat manusia. Kesadaran ini yang menuntun mereka senantiasa bersinergi dengan alam dan menjaga hubungan yang seimbang dan harmonis.

Kecintaan umat Hindu terhadap kerahayuan jagat melahirkan pelaksanaan 'ritual seni' seperti hadirnya Paruman Tapakan Barong di Pura Natarsari dalam pelaksanaan ritual Tapak Pertiwi. Ungkapan ini bermakna menyatunya alam atas atau swah loka dengan alam bawah atau bhur loka melalui kekuatan alam tengah atau bwah loka. Aktivitas ini dituang dalam ritual doa pemujaan atau tri sandiya agar setiap umat dapat melakukan, tidak menunggu adanya pelaksanaan ritual Tapak Pertiwi.

Bertemunya unsur kekuatan dewa lambang (bapa boma) dengan dewi (ibu bumi atau pertiwi) mengungkapkan gerak kehidupan makrokosmos ke mikrokosmos atau sebaliknya setiap waktu. Penghormatan bertemunya jalinan ke dua unsur energi kehidupan itu diwujudkan melalui pelaksanaan ritual Tapak Pertiwi dalam siklus kecil (alit/nista), sedang (madiya), dan besar (agungl uttama).

\section{Kepustakaan}

Agung, A.A. Gde Putra. 2006. Peralihan Sistem Birokrasi dari Tradisional ke Kolonial. Yogyakarta: Pustaka Pelajar.

Anandakusuma, Sri Reshi. 1986. Kamus Bahasa Bali. Bali: CV Kayumas Agung.

Atmodjo, M.M. Sukarto K. 1986. "Pengertian Local Genius dan Relevansinya Dalam Modernisasi”, dalam Kepribadian Budaya Bangsa. Jakarta: Pustaka Jaya.

Bandem, I Made. 1991. Tari-Tarian Bali Dalam Upacara Agama Hindu Dharma. Denpasar: Parisada Hindu Dharma.

1992. Sakral dan Sekuler Tari Bali Dalam Transisinya. Denpasar: Sekolah Tinggi Seni Indonesia Denpasar.

Dibia, I Wayan. 1985. "Odalan of Hindu Bali: A Religious Festival, a Social Occasion, and a Theatrical Event", dalam Asian Theatre Journal. American: University and College Theatre, American Theatre Association ,1999. Selayang Pandang Seni Pertunjukan Bali. Bandung: Masyarakat Seni Pertunjukan Indonesia.

Hendropuspito O.C., D. 1983. Sosiologi Agama. Yogyakarta: Kanisius.

Kerepun, Made Kembar. 2007. Kelemahan dan Kekuatan Manusia Bali: Sebuah Otokritik. Denpasar: PT Empat Warna Komunikasi.

Kusmayati, A.M. Hermien. 1990. Makna Tari Dalam Upacara Di Indonesia. Yogyakarta: ISI Yogyakarta. 
Mantra, I.B. 1996. Landasan Kebudayaan Bali. Denpasar: Yayasan Dharma Sastra.

Pandji, IGB Nyoman. 1975/1976. Barong Di Bali Ditinjau dari Segi Rituil dan Perkembangannya Sebagai Seni Pertunjukan. Denpasar: Proyek Sasana Budaya Bali, Art Center.

Pendit, Nyoman S. 2001. Membangun Bali: Menggugat Pembangunan Bali untuk Orang Jakarta Melalui Jalur Pariwisata. Denpasar: BP Bali Post.

1993. Aspek-Aspek Agama Hindu: Seputar Weda dan Kebajikan. Jakarta: Pustaka Manikgeni.

Putra, I Gst. Agung Gde. t.t. Cudamani Tari Wali. Denpasar: Bali Offset.

Salad, Hamdy. 2000. Agama dan Seni: Refleksi Teologis Dalam Ruang Estetik. Yogyakarta: Yayasan Semesta dan CV Adipura.

Sanderson, Stephen K. 1993. Sosiologi Makro: Sebuah Pendekatan Terhadap Realitas Sosial. Jakarta: Rajawali Perss.

Sudarsana, I Ketut dan I Gst. Ngurah Putra. 2001. Pura Lubur Pucak Padang Dawa. Tabanan: Desa Bangli Baturiti.

2001. Raja Purana Pura Luhur Pucak Kembar. Tabanan: Desa Adat Pacung Baturiti.

Sudarsana, I Ketut dan I Wayan Widarsana. 2002. Pura Kahyangan Jagat Luhur Natar Sari. Tabanan: Desa Adat Apuan Baturiti.
Sujana, Nyoman Naya. 1994. "Manusia Bali di Persimpangan Jalan", dalam Dinamika Masyarakat dan Kebudayaan Bali. Denpasar: Bali Post.

Supriyono, Johannes. 2005. "Paradigma Kultural Masyarakat Durkheimian", dalam Teori-Teori Kebudayaan. Yogyakarta: Kanisius.

Sutrisno, Mudji (ed.) 2005. Teori-Teori Kebudayaan. Yogyakarta: Kanisius.

Titib, I Made. Teologi dan Simbol-Simbol Dalam Agama Hindu. Surabaya: Paramita.

Turner, Bryan S. 1991. Religion and Social Theory. London: Sage Publications Ltd.

Turner, Victor. 1977. The Ritual Process: Structure and Anti Structure. New York: Cornell University Press.

Triguna, I B Yudha. 1994. "Pergeseran dalam Pelaksanaan Agama: Menuju Tattwa", dalam Dinamika Masyarakat dan Kebudayaan Bali. Denpasar: Bali Post.

Wiana, Ketut. 1993. Bagaimana Umat Hindu Menghayati Tuhan. Jakarta: Pustaka Manikgeni Permai Raya V.

Widana, I Gusti Ketut. 2002. Mengenal Budaya Hindu di Bali. Denpasar: PT Bali Post. 